\title{
A FORMAÇÃO DOCENTE E AS ORGANIZAÇÕES INTERNACIONAIS: Uma agenda focada na performatividade dos professores e na eficácia escolar ${ }^{1}$
}

\author{
Ana Maria Alves Saraiva \\ Universidade Federal de Minas Gerais (UFMG) \\ Juliana de Fátima Souza \\ Universidade Federal de Minas Gerais (UFMG)
}

\begin{abstract}
Resumo
O objetivo do artigo consiste em evidenciar o papel de organizações internacionais na construção de uma nova agenda para a formação docente, em especial no âmbito da América Latina e Caribe, enquanto manifestação de uma regulação transnacional das políticas educativas, que se apoia na eficácia escolar como medida de qualidade do sistema. Os referenciais teóricos predominantes são os da regulação educacional (João Barroso e Christian Maroy), com ênfase na regulação transnacional, e a ideia de Agenda Globalmente Estruturada para a Educação, desenvolvida por Roger Dale. Em termos metodológicos, o estudo contemplou documentos acerca da profissão e formação docentes elaborados no âmbito da Organização para a Cooperação e Desenvolvimento Econômico (OCDE), da Organização das Nações Unidas para a Educação, a Ciência e a Cultura (Unesco) e da Oficina Regional de Educação para a América Latina e o Caribe (Orealc) entre os anos de 2010 e 2018. Constatou-se que essas organizações contribuem para um isomorfismo das políticas de formação docente ao redor do mundo, que são cada vez mais direcionadas segundo uma cultura de performartividade e de avaliação de resultados.
\end{abstract}

Palavras-chave: formação docente; regulação educacional; organizações internacionais.

\begin{abstract}
The aim of the article is to highlight the role of international organizations in building a new agenda for teacher training, especially in Latin America and the Caribbean, as a manifestation of transnational regulation of education policies, which relies on school effectiveness as a measure of quality of the system. The predominant theoretical references are those of educational regulation (João Barroso and Christian Maroy), with emphasis on transnational regulation, and the idea of a Globally Structured Agenda for Education, developed by Roger Dale. In methodological terms, the study included documents on the profession and teacher training prepared within the Organization for Economic Cooperation and Development (OECD), the United Nations Educational, Scientific and Cultural Organization (UNESCO) and the Regional Workshop on Education for Latin America and the Caribbean (Orealc) between the years 2010 and 2018. It was found that these organizations contribute to an isomorphism of teacher training policies around the world, which are increasingly directed according to a culture of performance and evaluation of results.
\end{abstract}

Keywords: teacher training; educational regulation; international organizations. 


\section{Introdução}

O presente artigo objetiva evidenciar o papel de organizações internacionais (OIs) na construção de uma nova agenda para a formação docente, em especial no âmbito da América Latina e Caribe, enquanto manifestação de uma regulação transnacional das políticas educativas, que se apoia na eficácia escolar como medida de qualidade do sistema.

A discussão se insere no contexto da Nova Gestão Pública (NGP) e dos novos modos de gerenciamento dos sistemas escolares propostos nas décadas de 1980 e de 1990, que apresentam a eficácia e a eficiência como princípios norteadores da gestão educacional (VERGER e NORMAND, 2015; OLIVEIRA, 2019). Enquanto a eficiência é tratada como um conceito econômico relativo ao sistema, como uma prestação de contas referente ao serviço ofertado à sociedade em contrapartida do valor financeiro aplicado; a eficácia tem sido disseminada como um conceito escolar, projetado em seus sujeitos - sobretudo diretores e professores - que devem alcançar as metas de desempenho estabelecidas pelos governos e, ainda, corresponder às novas necessidades da sociedade da informação e do conhecimento, no sentido da formação para o trabalho.

Tal quadro exige repensar e transformar a profissão docente segundo os conceitos e práticas da NGP, modelo este que têm sua popularidade e viabilidade preparadas de forma discursiva por instituições como a Organização Mundial para a Cooperação e o Desenvolvimento Econômico (OCDE), a Organização das Nações Unidas para a Educação, a Ciência e a Cultura (Unesco) e, no âmbito regional, a Oficina Regional de Educação para a América Latina e Caribe (Orealc). Através de estratégias e ações coordenadas, essas organizações buscam construir uma agenda comum em torno de dois objetivos centrais excelentes professores e escolas eficazes - desempenhando um papel importante no direcionamento e justificação das reformas e políticas educacionais nos níveis nacionais e locais.

Observa-se, entretanto, que a ideia que circula internacionalmente sobre professores excelentes está fortemente associada a uma cultura de performatividade e que os docentes são cada vez mais direcionados a corresponderem a uma gestão para resultados, devendo reorientar suas práticas de modo a garantir a melhoria da performance dos estudantes nas avaliações de desempenho em larga escala. Trata-se, assim, de um movimento no qual a responsabilidade pelo alcance das metas e as críticas pelo insucesso são dirigidas, em grande parte, aos professores; ignorando-se que o desempenho é resultado de um conjunto de outros fatores escolares, tais como a gestão, a infraestrutura e o currículo, e também de fatores domésticos bastante significativos como o capital cultural, o acompanhamento familiar das crianças nas atividades, a alimentação e a moradia adequadas, etc (DARLINGHARMMOND, 2015, p. 133).

Para melhor elucidar essa problemática, este texto está organizado da seguinte forma: a primeira parte aborda o modo como as OIs operam para a circulação e transferência de políticas educacionais, na perspectiva de uma regulação transnacional; a segunda especifica as principais temáticas referentes à formação docente que tem sido objetos de debate nos últimos anos em fóruns e documentos organizados pela OCDE, pela Unesco e pela Orealc; a 
terceira parte discute a gênese e o desenvolvimento da noção de eficácia na educação e o processo de convergência das preconizações internacionais com a construção de uma agenda da política educacional baseada na escolha da eficácia como medida de “qualidade” da educação, o que implica uma nova designação para esse conceito que vem ao longo das últimas décadas sendo utilizado como parâmetro para a tomada de decisão política.

Os referenciais analíticos predominantes neste estudo são a teoria da regulação educacional (BARROSO, 2004, 2005; MAROY, 2011a, 2011b) e a ideia de uma Agenda Globalmente Estruturada para a Educação (DALE, 2004, 2010), aos quais está subjacente a ideia de que as políticas se movem entre os países e ao redor do globo. Neste sentido, considera-se que a definição das políticas de educação evoluiu a uma natureza multiescalar, na qual instituições de naturezas distintas e poderes assimétricos (Estados, OIs, mercado, comunidades, etc.) interagem em níveis transnacionais, nacionais e locais. Não se trata de desconsiderar a relevância das dinâmicas locais, mas sim de analisa-las em perspectiva com as escalas regionais e globais e de interpretar as múltiplas conexões que se interpõem; compreendendo a política, ao final, como uma construção de caráter compósito.

No que tange à Agenda Globalmente Estruturada para a Educação (AGEE), Dale (2004) destaca que as forças supranacionais influenciam cada vez mais diretamente as agendas nacionais, movidas, sobretudo, por interesses de ordem econômica. De acordo com o autor, há uma tendência a uma padronização global de normas centrais do campo da educação, no que se refere à sua forma de organização, à estandardização dos processos de formação e currículos, a maior relevância dada às avaliações de resultados, dentre outras questões estruturais, incluindo a concepção sobre a profissão docente e sobre as finalidades da educação no panorama da globalização.

Em termos metodológicos, empreendeu-se uma análise de conteúdo de documentos gerados no âmbito da OCDE, da Unesco e da Orealc, entre os anos de 2010 e de 2018, acerca do tema da profissão docente e que se encontram disponíveis nos respectivos sites institucionais.

\section{As Organizações Internacionais e a Educação}

A intensificação da regulação transnacional e a centralidade das organizações internacionais como formuladores de políticas no campo educacional constituem um movimento crescente desde os anos de 1980, em convergência com os processos de reforma do Estado, no âmbito da Nova Gestão Pública, e da reestruturação capitalista, na perspectiva da mundialização do capital. Como salienta Carvalho (2016, p. 670), “os governos nacionais confrontam-se com o alargamento do campo de ação das organizações internacionais, cujos questionamentos percebem ora como obrigações, ora como recursos indispensáveis para dirigir e administrar os sistemas educativos”.

Dentre essas organizações, destacam-se o Banco Mundial, que passou a atuar mais fortemente na América Latina e Caribe desde a ascensão de governos neoliberais nos anos de 1980 e 1990, provocando reformas educativas como condicionalidade de empréstimos 
oferecidos aos países da região; a Organização Mundial do Comércio, que, ao incluir, no início dos anos 2000, a educação na lista de serviços internacionalmente negociáveis, forjou uma discussão sobre a educação na perspectiva de commodities e não como direito do cidadão; a OCDE, que sobretudo a partir dos anos de 1990 tem direcionado esforços específicos para a educação, tendo em vista o papel deste campo para o crescimento econômico; e a Unesco, que desde sua fundação (1945) infere sobre a educação como direito na perspectiva da qualidade de vida para todos os cidadãos, mas que desde fins do século XX tem promovido um discurso de qualidade de resultados em detrimento da qualidade de processos de aprendizagem, com efeitos também sobre a formação e a profissão docentes.

As quatro OIs relacionadas atuam na construção da ação pública, inspirando, induzindo e propondo adaptações de políticas e ações educativas, com discursos contextualizados nos níveis nacionais com distintas camadas de complexidade, mediação e resistência. Para os fins deste artigo, privilegia-se o estudo sobre o modo como operam duas organizações específicas: a OCDE, por constituir hoje ator central no direcionamento e justificação das reformas e políticas educacionais ao redor do mundo; a Unesco, com ênfase na Orealc, a fim de se evidenciar a permeabilidade da América Latina às orientações formuladas e a convergência do discurso regional com uma agenda globalmente estruturada para a educação.

Antes, porém, de apresentar como a OCDE e a Unesco organizam suas atividades relacionadas ao campo educativo, vale salientar algumas das múltiplas estratégias discursivas de mobilização de ambas as OIs. Primeiramente, as duas podem ser classificadas como organizações periciais, ou seja, trata-se de organizações que aparentam neutralidade política e neutralidade científica, uma vez que suas preconizações e recomendações acerca da educação são formuladas por experts - por especialistas externos ao campo e não vinculados diretamente a instituições ou Estados. Neste sentido, a fabricação de agendas para o governo da educação se dá em nome de um conhecimento pericial que, como assevera Carvalho (2016, p. 673), tem um caráter singular por “autorizar-se a si mesmo”, na medida em que a construção das pesquisas, das análises e das publicações “é feita por equipes e organizações que coletivamente validam a sua própria perícia e que não fazem prova da sua qualidade no contexto das revistas especializadas nem da avaliação pelos pares". Nessa mesma perspectiva, Sotiria Grek (2016, p. 711) classifica este tipo de OIs como "atores do conhecimento”, que se baseiam na ideia de tecnicidade e de despolitização para exercerem poder na regulação transnacional.

Em segundo lugar, os discursos propagados internacionalmente conferem legitimação e justificação para reformas educativas (VERGER e NORMAND, 2015; VERGER, PARCERISA e FONTDEVILLA, 2018). Se, por um lado, observa-se a produção de um isomorfismo de políticas das quais os atores nacionais dificilmente podem escapar, estabelecendo padrões normativos comuns que são raramente questionados; por outro, as OIs desenvolvem instrumentos de políticas que têm natureza polissêmica e que são semioticamente maleáveis, se adequando a distintos contextos nacionais. Assim, permitem a mobilização seletiva em função das especificidades dos contextos de acolhimento e contribuem para legitimar programas que de outro modo encontrariam mais resistência. 
Outra característica própria do processo de modelagem de políticas das organizações internacionais, que se coaduna e reforça as lógicas anteriores, consiste no uso nuclear da informação e das estatísticas como tecnologias de governo. Nesse sentido, os números são tidos como expressão da verdade e fornecem evidências simplificadas para contextos extremamente multifacetados. Conforme assinalam Popkewitz e Lindblad (2001, 2016), a razão embutida nas estatísticas é a domesticação do acaso e da mudança; de modo que fenômenos complexos são estabilizados para ordenar os fenômenos passíveis de observação, cálculo e administração de reformas:

Os números ordenam e disciplinam sobre o que se vê e sobre o qual se pensa e age. [...] Não sem contestações, as categorias e grandezas estatísticas entremeiamse a outros discursos para formar um sistema de razão que rege [...] a maneira segundo a qual constituem-se problemas sobre os quais se deve agir e ordena os objetos e características das pessoas sobre as quais se deve agir, as relações por meio das quais causas são determinadas e problemas remediados e os caminhos para as próprias possibilidades de mudança. (POPKEWITZ e LINDBLAD, 2001, p. 112)

As organizações internacionais atuam ainda por meio da referenciação e benchmarking, disseminando melhores práticas no campo das políticas educacionais. Nesse esforço, selecionam e apresentam "casos de sucesso" de países que conseguiram reformar seus sistemas e alcançar melhores resultados. Operam assim não apenas no poder de culpa, posicionando Estados mais ou menos comprometidos com a mudança no campo educativo na perspectiva gerencialista, mas também na esperança de que é possível avançar com a ajuda de peritos e com as lições aprendidas de outras nações (CARVALHO, 2016).

Consoante a esse aspecto, verifica-se a intervenção das OIs no sentido de se estabelecer uma mútua vigilância dos sistemas educativos no espaço competitivo mundial. Se antes os esforços de tais organizações concentravam-se em produzir estudos singulares sobre cada país, respeitando as especificidades nacionais, o movimento recente manifesta uma viragem comparatista, com o deslocamento do foco para a produção de instrumentos que permitam a comparação dos Estados uns com os outros em face de critérios estandardizados (CARVALHO, 2016).

Por fim, na impossibilidade de se explorar e se esgotar as múltiplas e cada vez mais sofisticadas formas pelas quais as OIs atuam como fontes de regulação transnacional, vale ressaltar que, de modo geral, o poder de modelagem dessas organizações se dá num exercício contínuo baseado em informação e persuasão. Tanto a OCDE quanto a Unesco contam, nesse processo, com um complexo setor de educação destinado a influir na construção das políticas educativas em diferentes contextos. 


\section{O setor educacional da OCDE}

O setor educacional da OCDE está estruturado em cinco áreas de trabalho, quais sejam: i) Mensuração de Resultados, que parte do princípio de que as políticas educacionais devem ser sempre baseadas em evidências; ii) Ensino e Aprendizagem, com a premissa de que o modo como os professores ensinam e os alunos aprendem são questões centrais no desenvolvimento de políticas educacionais; iii) Desenvolvimento e Uso de Competências, área mais diretamente relacionada à educação para o trabalho, justificando-se pela ideia de que o desenvolvimento de habilidades e competências é fundamental para um crescimento econômico impulsionado pela inovação; iv) Desenvolvimento e Implementação de Políticas, que analisa os sistemas educacionais dos países da OCDE e parceiros, com a intenção de ajuda-los na formulação e implementação de políticas que promovam a melhoria de tais sistemas; v) Inovação e o Futuro da Educação, que busca discutir tendências e fornecer aos formuladores de políticas uma compreensão sobre como o processo de inovação está se transformando e suas implicações para as políticas educacionais e de treinamento (OCDE, 2020).

Para efeitos deste artigo, é importante destacar alguns instrumentos e programas delineados especificamente nas áreas de Mensuração de Resultados e de Ensino e Aprendizagem da OCDE, que repercutem mais diretamente sobre a formação e profissão docentes. Na área de Mensuração de Resultados, tem-se a produção de estatísticas educacionais e indicadores que influenciam progressivamente as decisões políticas, tais como o relatório anual Education at a Glance, sobre o estado da educação no mundo, publicado desde 1998; e o Programa para Avaliação Internacional de Alunos (PISA, na sigla em inglês), que testa a cada três anos, desde os anos 2000, os conhecimentos em leitura, matemática e ciências de estudantes de quinze anos de diversos países. Já na área de Ensino e Aprendizagem destacam-se dois dispositivos que têm sido largamente utilizados pelos governos para justificarem mudanças nas políticas de formação, remuneração e carreira docente: a Pesquisa Internacional de Ensino e Aprendizagem (TALIS, na sigla em inglês), que foi aplicada pela primeira vez em 2008 e se repete a cada cinco anos, questionando professores e diretores escolares sobre as condições de trabalho e ambientes de aprendizagem em suas unidades educacionais; e as Cúpulas Internacionais sobre Profissão Docente, que são realizadas anualmente desde 2011, tendo como público-alvo ministros e especialistas em educação, para os quais são apresentadas recomendações políticas fundamentadas nos dados do Pisa e da Talis, principalmente.

As Cúpulas constituem, pois, aspecto central em nossa análise, na medida em que, conforme sinalizam seus organizadores, estas reuniões, bem como os seus relatórios, pretendem ser um trampolim para a discussão sobre políticas educacionais relacionadas à formação docente, "reunindo diferentes perspectivas em busca de objetivos comuns excelentes professores e escolas eficazes” (ASIASOCIETY, 2018). O Quadro 1 situa a problemática discutida no âmbito dessas reuniões internacionais, desde a primeira edição em 2011. 


\section{Quadro 1. Cúpulas Internacionais sobre Profissão Docente: Temática e Tópicos Centrais, OCDE (2011-2018)}

\begin{tabular}{|c|c|}
\hline Ano & Temática e Tópicos Centrais \\
\hline 2011 & $\begin{array}{l}\text { Construindo uma profissão docente de alto desempenho } \\
\text { Avaliação de professores } \\
\text { Adesão docente às reformas } \\
\text { Recrutamento e formação inicial } \\
\text { Sistemas de bonificação }\end{array}$ \\
\hline 2012 & $\begin{array}{l}\text { Preparando professores e desenvolvendo lideranças escolares para o século XXI } \\
\text { Equilíbrio entre demanda e oferta de professores } \\
\text { Preparação de professores para as habilidades requeridas no século XXI }\end{array}$ \\
\hline 2013 & $\begin{array}{l}\text { Professores para o século XXI } \\
\text { Usando a avaliação para melhorar o ensino } \\
\text { Procedimentos para avaliação de professores } \\
\text { Uso dos resultados da avaliação de professores } \\
\text { Rumo a uma abordagem da avaliação/accountability }\end{array}$ \\
\hline 2014 & $\begin{array}{l}\text { Equidade, excelência e inclusão na educação - lições políticas de todo o mundo } \\
\text { Desenvolver professores de alta qualidade para escolas com maiores necessidades }\end{array}$ \\
\hline 2015 & $\begin{array}{l}\text { Escolas para alunos do século XXI - lideranças fortes, professores confiantes, abordagens } \\
\text { inovadoras } \\
\text { Promover uma liderança escolar eficaz } \\
\text { Inovar para criar ambientes de aprendizagem do século XXI }\end{array}$ \\
\hline 2016 & $\begin{array}{l}\text { Ensinando excelência através da aprendizagem profissional e reforma política } \\
\text { Habilidades e qualidades do professor de sucesso } \\
\text { Ações efetivas do governo para implementar políticas educacionais } \\
\text { Professores profissionais, reformas de sucesso }\end{array}$ \\
\hline 2017 & $\begin{array}{l}\text { Empoderamento e capacitação de professores para a promoção da equidade e resultados para } \\
\text { todos } \\
\text { Empenhar-se para excelência sustentável e equidade na aprendizagem } \\
\text { Garantir estrutura e ambiente apropriado para aprendizagem em cada país }\end{array}$ \\
\hline 2018 & $\begin{array}{l}\text { Valorizando professores e elevando seus status: escolas no centro das comunidades } \\
\text { Como as comunidades podem ajudar } \\
\text { Pedagogias para o futuro } \\
\text { Bem-estar, confiança e eficácia dos professores }\end{array}$ \\
\hline
\end{tabular}

Fonte: Elaboração própria, com dados de AsiaSociety (2011-2018).

\section{O setor educacional da Unesco}

A Unesco, por sua vez, organiza suas atividades na área da educação em cinco eixos, quais sejam: i) Laboratório de Ideias, que busca antecipar e responder às novas tendências e necessidades em matéria de educação e elaborar políticas educativas baseadas em pesquisa e 
nas prioridades dos países; ii) Ação Normativa, que trata da elaboração de padrões, normas e diretrizes nos principais âmbitos da educação; iii) Centro de Intercâmbio de Informação, que busca promover o desenvolvimento, a aplicação e a difusão de políticas e práticas educativas exitosas; iv) Aumento da Capacidade, que objetiva proporcionar a cooperação técnica para que os Estados-membros desenvolvam suas capacidades com vistas a alcançar os objetivos nacionais no campo da educação; v) Catalizador da Cooperação Internacional, que intenta iniciar e promover o diálogo e o intercâmbio entre lideranças do setor educativo e os interessados na matéria (UNESCO, 2020).

Destacam-se dois instrumentos: o Instituto de Estatística da Unesco, sediado no Canadá, que possibilita o monitoramento e a comparação de dados sobre matrículas, docentes, financiamento e resultados da educação nos níveis básico e superior, dentre outras informações estatísticas de centenas de países; e a Força-Tarefa Internacional de Docentes para a Educação 2030. Trata-se de um grupo de trabalho especialmente criado com o objetivo de estabelecer um fórum internacional para se repensar a profissão e a formação docente, à similitude das Cúpulas da OCDE. Tem-se aqui como referência, contudo, não o crescimento econômico, mas sim os Objetivos de Desenvolvimento Sustentável (ODS), pactuados no âmbito das Nações Unidas, e o Marco de Ação para a Educação 2030, adotado por 184 paísesmembros da Unesco. No item 4, os ODS estabelecem o propósito de “assegurar a educação inclusiva e equitativa e de qualidade, e promover oportunidades de aprendizagem ao longo da vida para todas e todos" e mais especificamente o item 4c estabelece que até 2030 devese buscar “substancialmente aumentar o contingente de professores qualificados, inclusive por meio da cooperação internacional para a formação de professores, nos países em desenvolvimento, especialmente os países menos desenvolvidos e pequenos Estados insulares em desenvolvimento"2 (UNESCO, 2016).

O Quadro 2 relaciona as temáticas que vêm sendo discutidas nas reuniões anuais deste grupo, instalado pela Unesco, mas com o envolvimento de uma série de outros atores cada vez mais relevantes no campo educacional, como a própria OCDE, além de representantes de Estados, lideranças de think tanks, fundações privadas e organizações nãogovernamentais. O princípio de ação do grupo é o de que entre os numerosos determinantes da qualidade da educação e dos resultados da aprendizagem, a inclusão de um professor qualificado e motivado na sala de aula é o fator escolar mais importante. 
Quadro 2. Fórum de Diálogo sobre Políticas: Temática e Tópicos Centrais, Força-Tarefa Internacional de Docentes para a Educação (2010-2018)

\begin{tabular}{|c|c|}
\hline Ano & Temática e Tópicos Centrais \\
\hline 2010 & $\begin{array}{l}\text { Fornecer professores para a Educação para Todos (EPT): questões de qualidade } \\
\text { Resultados de aprendizagem } \\
\text { Relevância da formação segundo o contexto socioeconômico } \\
\text { Planejamento eficiente e alocação de recursos nas políticas docentes }\end{array}$ \\
\hline 2011 & $\begin{array}{l}\text { Garantir a equidade nas políticas e práticas dos países para fornecer professores de qualidade } \\
\text { para a consecução dos objetivos da EPT até } 2015 \\
\text { Desenvolvimento profissional e status } \\
\text { Educação de qualidade para o século XXI: gestão e desafios instrucionais } \\
\text { Financiamento }\end{array}$ \\
\hline 2012 & $\begin{array}{l}\text { Três anos de parceria global para enfrentar o desafio do professor, três anos a partir do } \\
\text { benchmark } 2015 \text { da EPT: conquistas e perspectivas } \\
\text { Formação de professores e desenvolvimento profissional } \\
\text { Status dos professores e condições de trabalho } \\
\text { Inclusão nas políticas e práticas docentes } \\
\text { Professores e formação para o desenvolvimento sustentável } \\
\text { Monitoramento e avaliação das políticas e práticas dos professores }\end{array}$ \\
\hline 2013 & $\begin{array}{l}\text { A gestão da formação de professores - tendências em políticas e práticas: o que funciona, por } \\
\text { que e para quem? } \\
\text { Formação de professores: estruturas, conteúdos e resultados } \\
\text { Atrair e reter professores } \\
\text { Financiamento e gestão da formação de professores } \\
\text { Gestão da formação de professores em contextos pós-conflito e pós-desastre }\end{array}$ \\
\hline 2014 & $\begin{array}{l}\text { Professores na agenda internacional de educação pós-2015: quais políticas, práticas e } \\
\text { ferramentas para o professor segundo o público-alvo? } \\
\text { Inclusão e equidade nas políticas e práticas docentes } \\
\text { Inovação no ensino e formação de professores } \\
\text { Status profissional dos professores }\end{array}$ \\
\hline 2015 & $\begin{array}{l}\text { Implementando a meta da docência nos Objetivos de Desenvolvimento Sustentável para a } \\
\text { Educação } 2030 \\
\text { Formação de Professores (pré-serviço, em serviço e desenvolvimento profissional; inovação e } \\
\text { pedagogia) } \\
\text { Ensinar e aprender } \\
\text { Financiamento da formação e desenvolvimento de professores } \\
\text { Monitoramento e avaliação no desenvolvimento de professores }\end{array}$ \\
\hline 2016 & $\begin{array}{l}\text { Motivando os professores, o que sabemos e o que precisamos para alcançar a Agenda da } \\
\text { Educação 2030? } \\
\text { Motivação e formação de Professores } \\
\text { Motivação do professor e condições de trabalho do professor (no nível da escola) } \\
\text { Governança educacional e motivação dos professores } \\
\text { Perfis de professores e alunos e motivação dos professores }\end{array}$ \\
\hline
\end{tabular}




\begin{tabular}{|l|l|}
\hline $\mathbf{2 0 1 7}$ & $\begin{array}{l}\text { Ensinar: uma profissão } \\
\text { Conhecimento e competências } \\
\text { Governança } \\
\text { Princípios e responsabilização } \\
\text { Abordando a diversidade }\end{array}$ \\
\hline $\mathbf{2 0 1 8}$ & $\begin{array}{l}\text { Fortalecendo a formação de professores: um pré-requisito para ensino, formação e } \\
\text { aprendizagem de qualidade } \\
\text { Conhecimento, habilidades e competências para o desenvolvimento de professores } \\
\text { Formação de professores: habilidades e competências para o trabalho } \\
\text { Promoção da igualdade de oportunidades de aprendizagem para todos pela formação de } \\
\text { professores } \\
\text { Formação de professores: aprendizagem digital e desenvolvimento profissional contínuo }\end{array}$ \\
\hline
\end{tabular}

Fonte: Elaboração própria, com dados de International Task Force on Teachers for Education 2030 (2020).

\section{A estratégia regional para docentes da Orealc/Unesco}

No nível regional, a Unesco opera através da Oficina para a Educação da América Latina e Caribe (Orealc), também alinhada aos Objetivos de Desenvolvimento Sustentável (ODS) e ao Marco de Ação para a Educação 2030, que dentre outras questões, destaca que

A falta e/ou a inadequação de apoio e desenvolvimento profissional contínuo de professores e padrões nacionais para a profissão docente são fatores-chave que contribuem para a baixa qualidade dos resultados de aprendizagem. Sistemas educacionais bem-sucedidos, que garantem a qualidade e a equidade, concentraram-se em contínuo desenvolvimento profissional que apoia a aprendizagem e o aperfeiçoamento dos próprios professores ao longo de suas carreiras. (UNESCO, 2016, p. 54)

Assim como no caso dos Fóruns de Diálogos de Políticas, contudo, a ação da Orealc para a formação docente antecede o lançamento dos ODS e se fazia antes orientada pelos Objetivos de Desenvolvimento do Milênio. Foi nesse contexto ampliado que se construiu o Projeto Estratégico Regional sobre Docentes para a América Latina, que desde 2011 tem abordado de maneira sistemática temas que cruzam o desafio de desenhar políticas para o fortalecimento da profissão docente em prol do melhoramento da qualidade da educação para todos, como assinala a Unesco-Orealc (2015, p. 15).

Esse projeto buscou discutir quatro grandes dimensões: formação inicial; formação continuada e desenvolvimento profissional; carreira docente; e instituições e processos de políticas docentes. O Quadro 3 elenca as principais publicações derivadas dessas discussões: 
Quadro 3. Estratégia Regional sobre Docentes, Orealc (2011-2018)

\begin{tabular}{|c|l|}
\hline Ano & \multicolumn{1}{c|}{ Temática e Tópicos Centrais } \\
\hline $\mathbf{2 0 1 1}$ & $\begin{array}{l}\text { Institucionalizando a profissão docente } \\
\text { Cumprimento das normas estabelecidas para a profissão docente } \\
\text { Influências externas e a necessidade de um “novo" docente } \\
\text { Formação ao longo da vida }\end{array}$ \\
\hline $\mathbf{2 0 1 2}$ & $\begin{array}{l}\text { Formação para educação inclusiva e sustentável } \\
\text { Produção e utilização de indicadores para melhoria da qualidade da educação e da formação }\end{array}$ \\
\hline $\mathbf{2 0 1 3}$ & $\begin{array}{l}\text { Promover o ingresso dos melhores candidatos à profissão docente } \\
\text { Aumentar as exigências para ingresso nos cursos de formação inicial } \\
\text { Fortalecer a qualidade da formação e dos formadores }\end{array}$ \\
\hline $\mathbf{2 0 1 5}$ & $\begin{array}{l}\text { Experiência exitosas na formação de professores } \\
\text { Desenvolvimento das lideranças dos diretores escolares }\end{array}$ \\
\hline $\mathbf{2 0 1 6}$ & $\begin{array}{l}\text { Meritocracia e desenvolvimento profissional docente } \\
\text { Ampliação do conceito de desenvolvimento profissional docente } \\
\text { Processos de avaliação dos professores }\end{array}$ \\
\hline $\mathbf{2 0 1 7}$ & $\begin{array}{l}\text { Formação e desenvolvimento profissional docente } \\
\text { Formação de professores para primeira infância } \\
\text { Incentivos não monetários para carreira docente }\end{array}$ \\
\hline $\begin{array}{l}\text { Formação inicial de professores para cidadania } \\
\text { Educação para desenvolvimento sustentável } \\
\text { Currículo da formação com maior clareza e sistematização }\end{array}$ \\
\hline $\mathbf{2 0 1 8}$ & $\begin{array}{l}\text { Garantir uma educação inclusiva para todos e promover oportunidades de aprendizagens de } \\
\text { qualidade e equitativas } \\
\text { Competências para o século XXI e Educação inclusiva como disciplinas e não temas } \\
\text { transversais }\end{array}$ \\
\hline
\end{tabular}

Fonte: Elaboração própria, com dados de UNESCO-OREALC (2011-2018).

De um modo geral, pode-se afirmar que as preconizações produzidas pelos três atores em evidência - OCDE, Unesco e Orealc - corroboram para a construção de uma agenda comum de profissão docente pautada na eficácia como medida escolar. Trata-se de uma agenda transnacional de proposições para o que se denomina a escola do século XXI, que trata principalmente das seguintes temáticas: desenvolver a liderança eficaz dos diretores, formar professores de alta qualidade e reconhecer a necessidade de um "novo" professor capaz de formar os alunos para as competências exigidas no século XXI. Nesse sentido, tratamos nesta última parte do texto das configurações assumidas pela eficácia ao longo das últimas décadas, compreendendo que a análise da sua gênese e de seu desenvolvimento pode auxiliar no entendimento da sua centralidade nas preconizações e recomendações exportadas pelas OIs. 


\section{A eficácia como medida escolar: da escola eficaz aos professores eficazes}

Vale lembrar que as reflexões acerca da eficácia da escola não constituem exatamente uma novidade, tendo ganhado força a partir da década de 1970. A entrada do conceito no universo escolar remete à linha de pesquisa denominada escola eficaz. Aponta-se essa emergência como um movimento de reação às teses que questionavam a efetividade da escola como instituição promotora de alguma forma de justiça social (COLEMAN et al, 1966; BOURDIEU e PASSERON, 1970; ILLICH, 1971). Como contraponto a esse questionamento da escola e, em certa medida, às metodologias utilizadas até então nas pesquisas educacionais, ganha espaço a pesquisa sobre escola eficaz, que buscava identificar fatores e características organizacionais das instituições educacionais que apresentavam um desempenho quantitativo nos testes de avaliação superior à media de outras escolas com características discentes muito parecidas, e que seriam alçadas então à condição de escolas eficazes (SAMMONS, HILLMAN e MORTIMORE, 1995; SAMMONS, 1999).

O caráter positivista e fortemente determinista da abordagem metodológica que caracterizava essas pesquisas, que compreendiam a eficácia como um conceito autocentrado, que não estabelecia uma relação diferenciadora com outras dimensões como origem social, sexo, raça, etnia e localização territorial da escola, dificultou a sua disseminação como um instrumento a ser mobilizado para a melhoria da qualidade dos sistemas (MONS, 2008).

Em um período subsequente, com as reformas da década de 1990 (OLIVEIRA, 2000, 2006) e a emergência da NGP, o conceito de eficácia na educação é retomado em outras bases. Essa transição conta com as organizações internacionais como OCDE e Unesco como agências difusoras de uma nova concepção de Estado na orientação da política educacional, identificado como Estado gerencial pois passa a organizar a educação a partir do estabelecimento de metas quantitativas, da regulação por resultados e da construção de escalas de desempenho dos alunos comparáveis ao longo do tempo tanto no contexto nacional quanto internacional. Essa perspectiva vai orientar a criação de sistemas nacionais de avaliação na maioria dos países da América Latina, que são necessários para alimentar a regulação por resultados.

O Estado gerencial traz subjacente a sua estruturação uma nova forma de justiça, a justiça escolar ${ }^{3}$, proposta a partir das críticas ao ideal de igualdade de oportunidades como promotor da mobilidade social pelo acesso à educação. Essa transição de um ideal de igualdade (o acesso à educação para todos) para um ideal de equidade (a igualdade no acesso com o reconhecimento das diferenças que influenciam na permanência e no desempenho) é observada nos documentos do Quadro 1, onde o termo equidade e educação na perspectiva inclusiva são recorrentes.

Para Derouet (2009, p. 15), mesmo com essa transição há uma ambiguidade na forma de justiça escolar proposta pela NGP, que propõe "primeiro a igualdade de resultados (o estabelecimento de metas únicas para todas as escolas) e com as dificuldades apresentadas para obtenção dessas metas, a equidade retorna, sem que a igualdade saia de cena”.

É justamente esse caráter avaliador assumido pelo Estado na NGP que vai deslocar a eficácia da condição de um conjunto de variáveis que modelavam as características e o clima 
de uma determinada escola, como era na perspectiva da escola eficaz, para se constituir em uma medida de desempenho que classifica todas as escolas em uma única escala (igualdade de resultados), reduzindo o funcionamento da escola à dimensão única da eficácia. A promoção de justiça pela educação passa a ser representada por uma medida estatística, determinando que a escola seja mais ou menos justa conforme o seu nível de proficiência nos exames externos. Esse deslocamento do ideal de justiça pode ser percebido nos discursos de afirmação desse modelo, que substituem a demanda histórica do direito à educação pelo direito aos resultados de aprendizagem.

Os indicadores tendem então a orientar e legitimar as decisões dos governantes, o que Normand (2009) nomeia como uma aritmética política das desigualdades. A produção dos indicadores demanda uma ação prévia de escolha das variáveis independentes de sua composição, definindo aquelas desigualdades que são justas ou aceitáveis e sobre as quais o Estado entende que os sistemas escolares não podem enfrentar a curto prazo.

Para Normand (2009, p. 331) as avaliações externas minimizam essas desigualdades, apresentando como resultado uma medida que permite classificar e posicionar as escolas em uma mesma escala, a despeito de suas diferenças. Dessa forma, como o resultado é apresentado por escola e os indicadores de proficiência não permitem identificar as singularidades de cada uma, entende-se que são muito parecidas em suas características (dependência administrativa, forma de contratação, formação exigida para ingresso dos professores, tempo de permanência dos alunos, grade curricular, etc) e que as diferenças nos resultados dizem respeito somente ao trabalho realizado no interior da escola, excluindo os sistemas de sua responsabilidade e disseminando uma ideia de que a melhoria dos sistemas depende da melhoria do indicador de cada escola, responsabilizando a unidade educacional, seus gestores e seus professores por essa tarefa.

Os docentes se tornam então público-alvo dos discursos e ações das organizações internacionais, que conferem ao professor um papel de centralidade para a melhoria da qualidade da educação. Conforme restou demonstrado nos quadros sínteses das problematizações estabelecidas pela OCDE, Unesco e Orealc, essa discussão se faz, entretanto, na perspectiva de um novo profissionalismo docente, mais pragmático e orientado para a melhoria de resultados de aprendizagem, que por sua vez são medidos em avaliações de larga escala.

\section{Formação inicial e continuada: Uma cultura mundial das boas práticas}

Nesse panorama, as avaliações nacionais e internacionais ascendem ao status de instrumentos de governo e, conforme analisa Derouet (2009),

as informações que elas produzem acabam servindo para elaboração de rankings e para alimentar uma regulação das ações por benchmarking. [...] A competição coloca em evidência [por exemplo] os excelentes resultados dos países escandinavos e asiáticos, resultados que passam a ser perseguidos por outros 
países, na perspectiva das boas práticas que são apresentadas como passíveis de transposição. (DEROUET, 2009, p. 19)

A mundialização das boas práticas na formação de professores reforça, assim, a responsabilização docente para a melhoria da qualidade da educação, na perspectiva dos resultados e da eficácia.

No processo de circulação internacional de políticas e práticas educacionais, as OIs enfatizam não apenas a importância da formação inicial, em geral enfatizando a necessidade de torna-la mais prática, com a formação pré-serviço; como também privilegiam os percursos de formação continuada. Emerge, portanto, a noção de educação e formação ao longo de toda vida, conceito que deriva do lugar de destaque que o conhecimento ocupa na sociedade globalizada e em rápida e constante transformação. Logo, os professores precisam renovar permanentemente os seus conhecimentos, sob o risco de se tornarem obsoletos. Daí a ênfase na capacidade do professor de formar o aluno para o século XXI.

Cabe ainda ressaltar que a formação inicial e continuada apoia-se no que as OIs denominam de Desenvolvimento Profissional Docente. Nestes termos, segundo Oliveira (2012),

a construção da profissão docente estaria assim dada, sobretudo, pela formação concebida como a possibilidade de aprendizagem permanente. [...] Os professores sendo, em última instância, os responsáveis por seu desenvolvimento profissional, que deve ser tomado como um dever e obrigação para a melhoria da educação em geral. (OLIVEIRA, 2012, p. 42)

Em relação especificamente à América Latina e Caribe, percebe-se na estratégia regional que os documentos pretendem um certo reconhecimento da realidade local ao mesclar objetivos e propostas que remetem àquelas desenvolvidas no âmbito das Cúpulas da OCDE e do Fórum de Diálogo de Políticas da Força-Tarefa Internacional de Docentes para a Educação 2030 - como a necessidade de um “novo” docente, formação ao longo da vida, promover o ingresso dos melhores candidatos à profissão docente, desenvolvimento das lideranças dos diretores escolares e competências para o século XXI - com àquelas elaboradas na Orealc, que reforçam temas como a formação para equidade e formação na perspectiva inclusiva e da cidadania.

Os docentes latino-americanos para o século XXI precisam formar-se e desenvolver-se profissionalmente para uma dupla tarefa: preparar os alunos para a sociedade globalizada e informatizada do futuro, na perspectiva da teoria do capital humano e, ao mesmo tempo, minimizar os efeitos das desigualdades sociais, afetivas e econômicas, exercendo o seu trabalho na perspectiva da justiça social. 


\section{Considerações finais}

Em síntese, pode-se afirmar que as organizações internacionais tais como a OCDE, a Unesco e a sua representação regional Orealc contribuem para uma atualização da ideia do capital humano, reconvertida em outros princípios de racionalização. Neste sentido, as avaliações internacionais, tais como o Pisa e outras comparações que se dão no nível transnacional, emergem como uma boa mensuração do investimento dos países em educação e pressionam a formação e profissão docentes para uma cultura de performatividade e de excelência de resultados. O professor empreendedor de si mesmo é o docente desejado e capaz de formar pessoas para o século XXI.

Ademais, em uma versão educativa, as OIs reeditam, em termos mais amplos, a relação histórica entre o Banco Mundial, o Fundo Monetário Internacional e a Comissão Econômica para a América Latina e o Caribe, que norteou e legitimou epistemologicamente a teoria da dependência a partir dos anos de 1960 e 1970. Percebe-se a ideia de que a condição de desigualdade identificada nas avaliações internacionais e desempenho entre os alunos do Sul e os alunos do Norte global só serão superadas a partir do cumprimento de uma agenda de tarefas definidas e disseminadas por aqueles que se encontram nos primeiros postos dos rankings que os indicadores da educação fabricam.

Entretanto, a transposição de políticas não é algo simples ou pouco mediado. Embora se observe o isomorfismo da política e uma agenda globalmente estruturada para a educação, as ideias que circulam internacionalmente serão sempre adaptadas e recontextualizadas conforme os contextos políticos, econômicos e culturais de cada Estado. O que garante um alto potencial de modelagem de políticas das OIs é justamente sua capacidade de aderência a distintas realidades nacionais.

Assim como ocorreu na segunda metade do século XX, os organismos internacionais e as agências de influência ramificam-se na América Latina e Caribe como propositores do futuro, portadores das recomendações de uma eficácia itinerante e transnacional. Entretanto, a despeito dos anos seguindo a cartilha das recomendações e das boas práticas, seguimos buscando um lugar distante na excelência numérica. Talvez nos sejam esclarecedoras as palavras de Aníbal Quijano, que destacou que “os grupos sociais, que dispõem dos recursos do poder geral na sociedade, não podem ocupar essa posição a não ser sob a base da existência de um setor de marginalidade social”.

\section{Notas}

1. Este artigo é resultado de estudos desenvolvidos no âmbito da Pesquisa: Políticas públicas para a melhoria do ensino médio: socialização científica, tradução e transferência de resultados, financiada pelo Edital 22/2016 (CNPq), e da Pesquisa Pós-Doutoral Processo nº 154019/2018-6 (PDJ/CNPq - Bolsista Juliana F. Souza).

2. As atividades da Unesco no campo da educação são norteadas, desde 2015, pelos Objetivos de Desenvolvimento Sustentável. Anteriormente, estavam orientadas pelos Objetivos de Desenvolvimento do Milênio, também pactuados no âmbito das Nações Unidas.

3. Para Dubet (2004) e Derouet (2009) ao estabelecer-se na perspectiva gerencial, o Estado abandona os ideais de igualdade plena, fragmentando a noção de justiça social em áreas distintas. No caso da educação, entende-se como noção de justiça 
não mais a igualdade de oportunidades, mas a igualdade de resultados, não tendo mais que se falar em justiça social pela educação, mas sim em justiça escolar, que é alcançada quando, apesar das diferenças, os alunos obtém resultados muito parecidos nas avaliações externas.

\section{Referências}

ASIASOCIETY. Improving teacher quality around the world. The 2011 International Summit on the Teaching Profession. New York: Asia Society, 2011. Disponível em $<$ AsiaSociety.org/teachingsummit>. Acesso em 02 de março de 2019.

. Teaching and leadership for the twenty-first century. The 2012 International Summit on the Teaching Profession. New York: Asia Society, 2012. Relatório disponível em $<$ AsiaSociety.org/teachingsummit>. Acesso em 02 de março de 2019.

. Teacher Quality. The 2013 International Summit on the Teaching Profession. New York: Asia Society, 2013. Disponível em < AsiaSociety.org/teachingsummit>. Acesso em 02 de março de 2019.

Excellence, Equity, and Inclusiveness. High Quality Teaching for All. The 2014 International Summit on the Teaching Profession. Wellington, New Zealand: Asia Society, 2014. Disponível em < AsiaSociety.org/teachingsummit>. Acesso em 02 de março de 2019.

Implementing Highly Effective Teacher Policy and Practice. The 2015 International Summit on the Teaching Profession. Banff, Canadá: Asia Society, 2015. Disponível em $<$ AsiaSociety.org/teachingsummit>. Acesso em 02 de março de 2019.

. Teachers' professional learning and growth: creating the conditions to achieve quality teaching for excellent learning outcomes. The 2016 International Summit on the TeachingProfession. Berlim, Alemanha: Asia Society, 2016. Disponível em $<$ AsiaSociety.org/teachingsummit>. Acesso em 02 de março de 2019.

Empowering and Enabling Teachers to Deliver Improved Equity and Outcomes for All. The 2017 International Summit on the Teaching Profession. Edimburg, Escócia: Asia Society, 2017. Disponível em <AsiaSociety.org/teachingsummit>. Acesso em 02 de março de 2019.

. Valuing our Teachers and Raising their Status. The 2018 International Summit on the Teaching Profession. Lisbon, Portugal: Asia Society, 2018. Disponível em $<$ AsiaSociety.org/teachingsummit>. Acesso em 02 de março de 2019.

BARROSO, João. Os novos modos de regulação das políticas educativas na Europa: da regulação do sistema a um sistema de regulações. Educação em Revista. Belo Horizonte: vol. 39, p. 19-28, jul. 2004.

. O Estado, a educação e a regulação das políticas públicas. Educação e Sociedade. Campinas: vol. 26, n 92 , out. 2005, p. 725-751.

BOURDIEU, Pierre; PASSERON, Jean-Claude. A reprodução. 3.ed. Rio de Janeiro: Francisco Alves, 1992.

CARVALHO, Luís Miguel. Intensificação e sofisticação dos processos da regulação transnacional em educação: o caso do Programa Internacional de Avaliação de Estudantes. Educação e Sociedade. Campinas, v. 37, n. 136, Sept. 2016, p. 669-683. 
COLEMAN, James S. et al. Equality of Educational Opportunity. Washington, DC, Department of Health, Education and Welfare, 1966.

DALE, Roger. Globalização e Educação: demonstrando a existência de uma "Cultura Educacional Mundial Comum” ou localizando uma “Agenda Globalmente Estruturada para a Educação”? Educação e Sociedade. Campinas, vol. 25, n. 87, maio/ago. 2004, p. 423-460.

A Sociologia da Educação e o Estado após a Globalização. Educação e Sociedade. Campinas: vol. 31, n 113, out/dez 2010, p. 1099-1120.

DARLING-HAMMOND, Linda. Can value added value to teacher evaluation? Educational Researcher, vol. 44, $n^{\circ}$ 2, p. 132-137.

DEROUET, Jean Louis. Les recompositions parallèles des formes de l'Etat et des formes de justice. In: DEROEUT, Jean Louis.; DEROUET, Marie. Claude. (Ed) Repenser la justice dans le domaine de l'education et de la formation. Lyon, INRP, 2009, p. 3-23.

DUBET, François. O que é uma escola justa?. Cad. Pesqui.. São Paulo: 2004, v. 34, n. 123, p. 539555.

GREK, Sotiria. Atores do conhecimento e a construção de novos cenários de governança: o caso da Direção-Geral de Educação e Cultura da Comissão Europeia. Educação e Sociedade. Campinas: 2016, vol.37, n.136, p.707-726.

ILLICH, Ivan. Sociedade sem escolas. $7^{\text {a }}$ edição. Petrópolis: Ed. Vozes, 1985.

INTERNATIONAL TASK FORCE ON TEACHERS FOR EDUCATION 2030. International Policy Dialogue Fora 2010-2018. Disponível em $<$ http://www.teachersforefa.unesco.org/v2/index.php/en/our-activities/policy-dialogue-andknowledge-sharing/international-policy-dialogue-fora>. Acesso em 18 de janeiro de 2020.

MAROY, Christian. Em direção a uma regulação pós-burocrática dos sistemas de ensino na Europa? In: OLIVEIRA, Dalila A. e DUARTE, Adriana. (org.) Politicas públicas e educação: regulação e conhecimento. Belo Horizonte: Fino Traço, 2011a, p. 19-46.

Regulação dos Sistemas Educacionais. In: VAN ZANTEN, Agnès. (org.). Dicionário de Educação. Petropolis: Vozes, 2011b, p. 688-693.

NORMAND, Romuald. Mesurer la justice en education: esquisse d'une arithmétique politique des inegalités. In: DEROEUT, Jean Louis; DEROUET, Marie Claude (Ed). Repenser la justice dans le domaine de l'education et de la formation. Lyon, INRP, 2009, p. 349-365.

MONS, Nathalie. Eficácia dos sistemas educativos (Verbete). In: van ZANTEN, Agnès (Coord). Dicionário de Educação. Petrópolis: Ed. Vozes, 2008, p. 296-304.

OCDE Organização para a Cooperação e Desenvolvimento Econômico. OCDE Areas of Work. Disponível em <http://www.oecd.org/education/>. Acesso em 18 de janeiro de 2020.

OLIVEIRA, Dalila A. Educação básica. Gestão do trabalho e da pobreza. Petrópolis, RJ: Vozes, 2000.

. A educação para além do capital. Educação e Sociedade. Campinas: v. 27, n. 97, p. 13731376, dez. 2006.

POLÍTICAS DE FORMAÇÃO E DESENVOLVIMENTO PROFISSIONAL DOCENTE: DA INTENÇÃO ÀS PRÁTICAS. XVI Encontro Nacional de Didática e Práticas de Ensino, ENDIPE -, FE/UNICAMP, Campinas, 2012, p. 30 a 50. 
A profissão docente no contexto da Nova Gestão Pública no Brasil. In: OLIVEIRA, Dalila A.; CARVALHO, Luis Miguel; LEVASSEUR, Louis; MIN, Liu; NORMAND, Romuald (Orgs.). Políticas Educacionais e a reestruturação da profissão do educador- perspectivas globais e comparativas. Petrópolis: Editora Vozes, 2019, p. 271-300.

POPKEWITZ, Thomas; LINDBLAD, Sverker. Estatísticas educacionais como um sistema de razão: relações entre governo da educação e inclusão e exclusão sociais. Educação e Sociedade. Campinas: v. 22, n. 75, p. 111-148, ago. 2001.

POPKEWITZ, Thomas; LINDBLAD, Sverker. A fundamentação estatística, o governo da educação e a inclusão e exclusão sociais. Educação e Sociedade. Campinas: v. 37, n. 136, p. 727-754, set. 2016.

SAMMONS, Pamela; HILLMAN, John; MORTIMORE, Peter. Key Characteristics of Effective Schools: A Review of Effectiveness Research. London: Office for Standards in Education (OFSTED), 1995.

SAMMONS, Pamela. As características-chave das escolas eficazes (1999). In: BROOKE, Nigel; SOARES, José Francisco (Orgs). Pesquisa em Eficácia Escolar: origens e trajetórias. Belo Horizonte: Editora UFMG, 2009.

UNESCO Organização das Nações Unidas para a Educação e a Cultura. Las tareas del Sector de Educación de Unesco. Disponível em <https://es.unesco.org/themes/education/aboutus/missions>. Acesso em 18 de janeiro de 2020.

. Declaração de Incheon e ODS 4 Marco de Ação da Educação 2030. Brasília: Escritório da Unesco, 2016. Disponível em <https://unesdoc.unesco.org/ark:/48223/pf0000245656_spa>. Acesso em 18 de janeiro de 2020.

UNESCO-OREALC Oficina Regional de Educação para a América Latina e Caribe. La institucionalización de las políticas docentes em América Latina. Chile, 2011. Disponível em $<$ www.unesco.org $>$. Acesso em 03 de fevereiro de 2020.

. MARCO ESTRATEGICO DE TRABAJO UNESCO, OFICINA REGIONAL DE EDUCACIÓN PARA AMERICA LATINA Y EL CARIBE OREALC/UNESCO SANTIAGO. Chile, 2012. Disponível em <www.unesco.org>. Acesso em 02 de fevereiro de 2020.

. Estado del arte y criterios orientadores para la elaboración de políticas de formación y desarrollo profesional de docentes de primera infancia en América Latina y el Caribe. Chile, 2013. Disponível em <www.unesco.org>. Acesso em 03 de fevereiro de 2020.

. Professores para una educación para todos. Chile, 2014. Disponível em $<$ www.unesco.org>. Acesso em 10 de fevereiro de 2020.

. Las carreras docentes em América Latina. La acción meritocrática para el desarollo professional. Chile, 2015. Disponível em <www.unesco.org>. Acesso em 03 de fevereiro de 2020.

. Perspectivas sobre Políticas Docentes en América Latina y el Caribe. Chile, 2016. Disponível em <www.unesco.org>. Acesso em 07 de fevereiro de 2020.

. La Formación Inicial Docente en Educación para la Ciudadanía en América Latina. Chile, 2017. Disponível em <www.unesco.org>. Acesso em 10 de fevereiro de 2020. 
Formación Inicial Docente em Competencias para el Siglo XXI y Pedagogías para la Inclusion em América Latina. Chile, 2018. Disponível em <www.unesco.org>. Acesso em 13 de fevereiro de 2020.

VERGER, Antoni; NORMAND, Romuald. Nueva gestión pública y educación: Elementos teóricos y conceptuales para el estudio de un modelo de reforma educativa global. Educação e Sociedade. Campinas: v. 36, n. 132, p. 599-622, set. 2015.

VERGER, Antoni; PARCERISA, Lluís; FONTDEVILA, Clara. Crescimento e disseminação de avaliações de larga e de responsabilizações baseadas em testes: uma sociologia política das reformas educacionais globais. Revista da FAEEBA Educação e Contemporaneidade. Salvador, v. 27, n. 53, set/dez. 2018, p. 60-82.

\section{Correspondência}

Ana Maria Alves Saraiva: Doutora em Educação. Professora Adjunta da Faculdade de Educação da Universidade Federal de Minas Gerais. Pesquisadora do Grupo de Estudos sobre Política Educacional e Trabalho Docente (GESTRADO).

E-mail: anasaraiva@ufmg.br

Juliana de Fátima Souza: Doutora em Educação. Pesquisadora do Grupo de Estudos sobre Política Educacional e Trabalho Docente (GESTRADO).

E-mail: jusouzarp@gmail.com

Texto publicado em Currículo sem Fronteiras com autorização das autoras 